\title{
Erratum: A political economy analysis of decision-making on natural disaster preparedness in Kenya
}

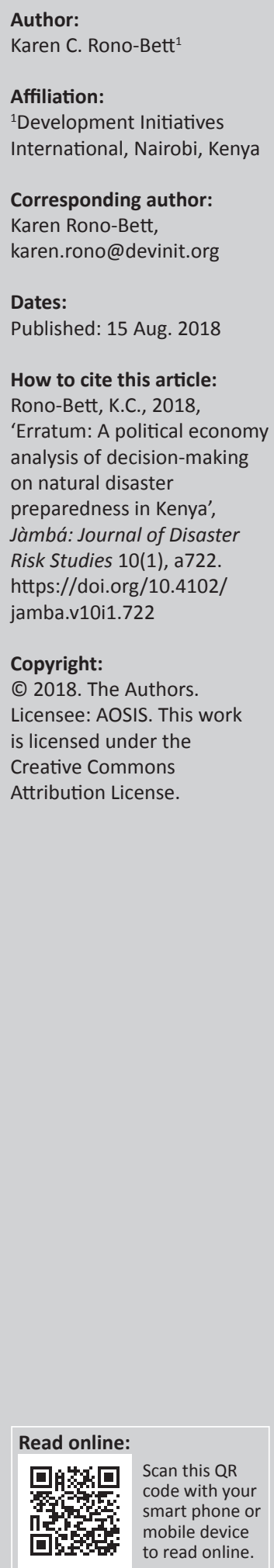

In the version of this article published earlier, the 'Acknowledgement' section contained the incorrect display of the funder's full name as 'Department for Internal Development (DfID)', which has been corrected to 'Department for International Development (DfID)'. The full 'Acknowledgement' statement is hereby updated and replaced with:

\section{Acknowledgements}

The author acknowledges the support from Dr Momodou Touray, Dr Moses Akali and Judith Randel who provided useful insights for this publication. This work is funded by the Department for International Development (DfID).

The publisher apologises for any inconvenience that this omission may have caused. 